\title{
The association between ambient temperature and preterm birth in Shenzhen, China: a distributed lag non- linear time series analysis
}

Zhijiang Liang ${ }^{1+}$, Yan Lin ${ }^{2+}$, Yuanzhu Ma ${ }^{1+}$, Lei Zhang ${ }^{3}$, Xue Zhang ${ }^{4}, \mathrm{Li} \mathrm{Li}^{5}$, Shaoqiang Zhang ${ }^{6}$, Yuli Cheng ${ }^{7}$, Xiaomei Zhou ${ }^{8}$, Hualiang Lin ${ }^{9}$, Huazhang Miao ${ }^{1}$ and Qingguo Zhao ${ }^{1 *}$

\begin{abstract}
Background: A few studies have examined the association between ambient temperature and preterm birth (PTB), and the results have been inconsistent. This study explored the association between ambient temperature and PTB in Shenzhen, China.

Methods: Data of daily singleton PTB, air pollution and meteorological variables from 2005 to 2011 were collected in Shenzhen. A distributed lag non-linear model (DLNM) was used to investigate the association of the low and high temperatures (1st, 5th, 95th, and 99th percentiles) with PTB.

Results: The median temperature was $24.5^{\circ} \mathrm{C}$ and the $1 \mathrm{st}, 5 \mathrm{th}, 95 \mathrm{th}$, and 99th percentiles of daily mean temperatures were 9, 12.5, 29.9 and $30.7^{\circ} \mathrm{C}$, respectively. The prevalence of singleton PTB was $5.61 \%$ in Shenzhen. The association between temperature and PTB was not linear. There was an immediate positive association of low temperature (1st and 5 th percentiles) and a negative association of high temperature (95th and 99th percentiles) with PTB. The effect of low temperature $9^{\circ} \mathrm{C}(1 \mathrm{st})$ on PTB on the current day was stronger than that of $12.5^{\circ} \mathrm{C}$ (5th), with a relative risk (RR) of 1.54 (95\% Cl: 1.36-1.75) and 1.49 (95\% Cl: 1.35-1.63), respectively. The cumulative RR (up to 30 days) of 9 and $12.5^{\circ} \mathrm{C}$ was 1.72 (95 \% Cl: 1.28-2.33) and 1.96 (95\% Cl: 1.60-2.39), respectively. The cumulative effects (up to 30 days) of high temperature (95th and 99th percentiles) on PTB were 0.69 (95\% Cl: 0.60-0.80) and 0.62 (95\% Cl: 0.52-0.74),

respectively. The cumulative effect (up to 30 days) of low temperatures on vaginal delivery PTB was lower than that of the cesarean section PTB with an RR of 1.58 (95 \% Cl: 1.12-2.22) and 1.93 (95 \% Cl: 1.21-3.08), respectively.
\end{abstract}

Conclusions: This study suggests that low temperature might be a risk factor, while high temperature might be a protective factor of PTB in Shenzhen.

Keywords: Preterm birth, Ambient temperature, Time-series study, Distributed lag non-linear model

\section{Background}

Preterm birth (PTB), defined as any live birth before 37 completed weeks of gestation, is an important public health problem [1]. It was estimated that there were 15 million PTB worldwide in 2010 [2]. Globally, PTB is the leading cause of newborn deaths and the second largest

\footnotetext{
*Correspondence: zqgfrost@126.com

${ }^{\dagger}$ Equal contributors

'Department of Public Health, Guangdong Women And Children Hospital, 521, 523 Xing Nan Street, Panyu District, 511442 Guangzhou, Guangdong, China

Full list of author information is available at the end of the article
}

direct cause of death only after pneumonia among children under five years, and over one million babies die annually from PTB-related complications [3].

The etiology of PTB remains unclear. Villar et al. proposed a PTB phenotype classification that incorporates five components-maternal conditions, fetal conditions, placental conditions, signs of parturition initiation, and the pathway to delivery [4]. The present findings suggest that the causes of PTB are a complex mix of genetic, behavioral, socio-economic and environment factors. Race [5, 6], maternal chronic infections and hypertension [7], 
maternal smoking $[8,9]$, maternal age [10-13], and air pollution $[14,15]$ all were identified as potential risk factors.

With the emerging interest in climate change and its health impacts, some researchers focused their studies on the association between the extreme high temperature and PTB. Although having been studied in some countries, the findings remained inconclusive. For instance, studies in the US [16, 17], Israel [18], Greece [19], Spain $[20,21]$, Australia [22, 23], Italy [24], and Sweden [25] reported a significant association between high temperature and PTB, but another US study [26] and some studies in England [27] and Germany [28] did not find any significant association between high temperature and PTB. The discrepancies may be due to the significant heterogeneities in the study design, population characteristics, and the data analysis of these studies.

The mechanism by which high temperature triggered PTB is unclear. There are several possible mechanisms. First, insufficient fluids in the mother due to high temperature can decrease the blood flow available to the fetus and induce uterine contractions [29]. Second, pregnant women may experience difficulty with thermoregulation and become dehydrated during the heat exposure, which may possibly result in a decrease in uterine blood flow and trigger labor [17]. Third, maternal heat stress may also trigger a release of hormones such as cortisol, which may in turn induce labor [18]. To our knowledge, few studies about the potential association between temperature and PTB have been carried out in China.

In the current study, we used a distributed lag nonlinear time series analysis to explore the association between the ambient temperature and PTB in Shenzhen, China. The aim of this study is to increase the awareness of policy makers and clinicians regarding the role of temperature exposure on PTB in Shenzhen.

\section{Methods}

\section{Study setting}

Shenzhen, located in southeastern China $\left(22^{\circ} 27^{\prime}\right.$ to $22^{\circ}$ $52^{\prime}$ north latitude), is a subtropical and coastal city; it has an area of $2000 \mathrm{~km}^{2}$, and belongs to subtropical oceanic monsoon climate with an average mean temperature of $23.0{ }^{\circ} \mathrm{C}$. The mean daily temperature of the coldest month in January is $15.4{ }^{\circ} \mathrm{C}$, and the mean daily temperature of the hottest month in July is $28.9{ }^{\circ} \mathrm{C}$. The data of air pollution, meteorological factors and birth registry with high quality are available, thus, we chose Shenzhen as the study site. Figure 1 shows the location of Shenzhen in Guangdong Province, China.

\section{Data source}

Daily data of preterm birth from January 1st, 2005 to December 31st, 2011 were collected from the birth registry database, which covered all midwifery clinics and hospitals in Shenzhen. Shenzhen maternal and children health information system has been constructed since 2000. One component of the system is birth certificate and all midwifery clinics and hospitals are using this system to report birth certificate through the network. The variables collected in birth registry database included date of birth, date of mother's last menstrual period (LMP), birth weight, infant sex, maternal age, delivery mode, etc. Gestational age was computed as the number of weeks between the date of the last menstrual period (LMP) and the date of birth.

Daily meteorological data were obtained from the Shenzhen Meteorological Bureau websites. The variables included daily mean temperature $\left({ }^{\circ} \mathrm{C}\right)$, relative humidity (RH, \%), and atmospheric pressure (BP, hpa).

Daily 24-hour average air pollution data were collected from the Environmental Monitoring Center located in the center of Shenzhen. Air pollution data included particulate matter with an aerodynamic diameter less than or equal to $10 \mathrm{um}\left(\mathrm{PM}_{10}\right.$, in $\left.\mathrm{ug} / \mathrm{m}^{3}\right)$, sulfur dioxide $\left(\mathrm{SO}_{2}\right.$, in $\left.\mathrm{ug} / \mathrm{m}^{3}\right)$ and nitrogen dioxide $\left(\mathrm{NO}_{2}\right.$, in $\left.\mathrm{ug} / \mathrm{m}^{3}\right)$.

Twin pregnancy and multiple pregnancies were excluded from this study. There were a total of 1,040,638 singleton live births from January 1st, 2005 to December 31st, 2011 in Shenzhen. The births with eligible gestational age (20-44 weeks) [30] accounted for $99.85 \%$ of the whole data. The births whose mother's LMP date was missing or implausible $(<20$ or $>44$ weeks $)$ accounted for $0.15 \%$ and were excluded from the analysis. Eligible live births with gestational age fewer than 37 weeks were considered preterm.

This study was approved by the medical ethics committee of Guangdong Women and Children Hospital. Data used in this study were anonymous and no individual identifiable information was available for the analysis.

\section{Statistical analysis}

A distributed lag non-linear model (DLNM) was used to simultaneously investigate the non-linear and delayed effects of temperature on daily preterm. The count of daily PTBs typically follows a Poisson distribution [31-33]. Quasi-likelihood Poisson regression in a generalized linear model was used to model the natural logarithm of daily counts of PTB as functions of predictor variables. This methodology was based on a "cross-basis" function, which allowed the non-linear effect of daily preterm variation at each lag and the non-linear effects across lag days to be estimated [34,35]. We initially constructed a "primary" model using the Akaike's Information Creterion (AIC) to choose the $\mathrm{df}$ (knots) for daily average temperature and lag in the "primary" models, and we found that a cubic b-spline with $5 \mathrm{df}$ for the daily mean 


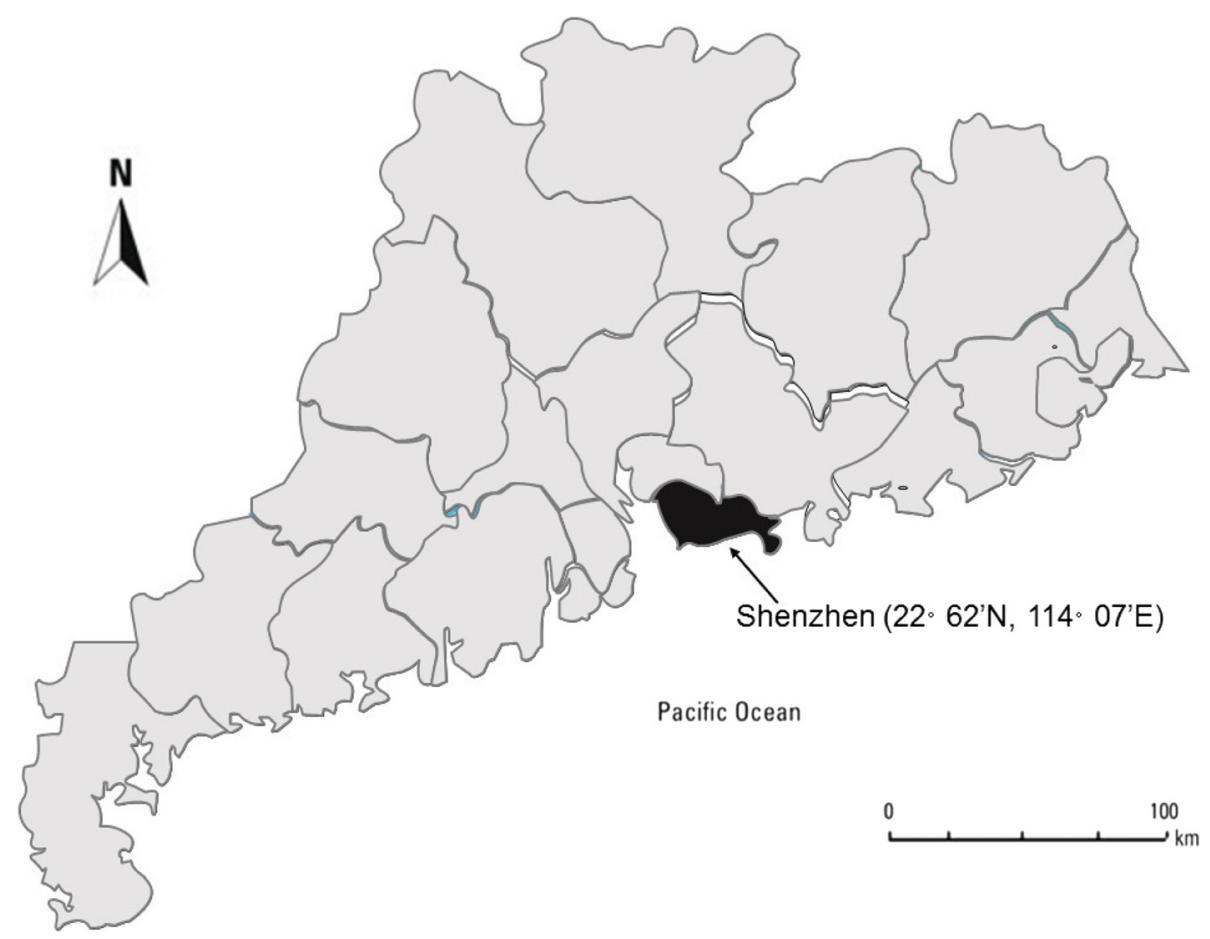

Fig. 1 The map of Shenzhen

temperature and $4 \mathrm{df}$ in the lag space produced the best "primary" model with lowest AIC value [35]. Potential confounding factors were controlled for in the model, such as an indicator for day of week (DOW), an indicator for public holiday $(\mathrm{PH})$, in order to control the seasonal and long-term trends and adjust for nontemperature aspects of weather, a natural cubic spline for day of the year (DOY, with $\mathrm{df}$ of $5 /$ year), and a natural cubic spline of relative humidity $(\mathrm{RH})$ and atmospheric pressure (BP) with the degrees of freedom (5 df), which was chosen by minimizing the AIC values [34, 36], and the linear function of air pollutants $\left(\mathrm{NO}_{2}\right.$, $\mathrm{PM}_{10}, \mathrm{SO}_{2}$ ) were introduced into the model simultaneously. The daily number of pregnancies at risk for preterm birth with $\log (\cdot)$ function (pregnancies between 20 and 36 weeks of gestation) was included in the model as offset $[33,37]$. The model used for the analysis could be specified as follows:

$$
\begin{aligned}
\log [\mathrm{E}(\mathrm{Yt})]=\alpha & +\mathrm{cb}(\mathrm{Temp}, 5, \operatorname{lag}, 4)+\mathrm{ns}(\mathrm{RH}, 5) \\
& +\mathrm{ns}(\mathrm{BP}, 5)+\mathrm{NO}_{2}+\mathrm{PM}_{10}+\mathrm{SO}_{2} \\
& +\mathrm{ns}(\mathrm{DOY}, \mathrm{df}=5 / \text { year })+\beta 1 * \mathrm{DOW} \\
& +\beta 2 * \mathrm{PH}+\beta 3 * \log (\mathrm{Zt})
\end{aligned}
$$

where Yt denotes the observed daily preterm count on day $\mathrm{t}, \alpha$ is the intercept, cb means the "cross-basis" function, ns(.) indicates a natural cubic splines for non-linear variables, $\mathrm{Zt}$ represents the daily number of pregnancies at risk for preterm birth on day $\mathrm{t}$ (pregnancies between
20 and 36 weeks of gestation), $\beta$ is the regression coefficient.

In addition, we conducted sensitivity analysis: use of alternative degrees of freedom (4, $6 \mathrm{df} /$ year) for temporal adjustment and change the degrees of freedom (4-7 df) for meteorological variables to evaluate the robustness of results.

According to a review [38], previous studies reported statistically significant association between the seasonal patterns and PTB. In order to test the validity of seasonal control in DLMN, we used a similar Poisson regression model as mentioned above and added month as a covariate into the model to compare the difference of the two models in controlling of season [39]. The model took the form:

$$
\begin{aligned}
\log [\mathrm{E}(\mathrm{Yt})]=\alpha & +\mathrm{cb}(\mathrm{Temp}, 5, \operatorname{lag}, 4)+\mathrm{ns}(\text { Month, } 5) \\
& +\mathrm{ns}(\mathrm{RH}, 5)+\mathrm{ns}(\mathrm{BP}, 5)+\mathrm{NO}_{2}+\mathrm{PM}_{10} \\
& +\mathrm{SO}_{2}+\mathrm{ns}(\mathrm{DOY}, \mathrm{df}=5 / \text { year }) \\
& +\beta 1 * \mathrm{DOW}+\beta 2 * \mathrm{PH}+\beta 3 * \log (\mathrm{Zt}) .
\end{aligned}
$$

Although an important advantage of the time-series design is the inherently controlling for the non-timevarying risk factors, even unknown or unrecorded [27]. In fact, the health effect of temperature is influenced by a variety of comprehensive factors including spatial distributions, exposure level, air pollution levels, and sociodemographic backgrounds. In the study of the association between the ambient temperature and PTB, the 
modification factors should be considered. The information on delivery mode, infant's gender and maternal age are available in our database. By analyzing the potential modification effect of those variables on the association between temperature and PTB, it can help to identify the susceptible groups and estimate the degree of influence in different population and introduce more targeted public health interventions.

In order to completely capture the association of overall temperature on PTB and adjust for potential harvesting effect [40], we assumed a longer lag days, up to 30 days, between the exposure and preterm. We used the median of daily mean temperature of $24.5{ }^{\circ} \mathrm{C}$ as the reference temperature to report the relative risk (RR, with $95 \%$ confidence intervals (CIs) of temperature (1st, 5th, 95th, and 99th percentiles of temperature) on PTB along specific lag days. This enabled us to obtain relative risk through the whole range of temperatures on different lag days. We also estimated the cumulative effects of low and high temperatures on preterm birth during lag periods (lag 0-30 days, where lag 0-30 represents the temperature on the day of preterm birth and the previous 30 days).

All statistical tests were two-sided and values of $P<$ 0.05 were considered statistically significant. The DLNM package [35] in R software Version 3.0.2 (R Development Core Team, 2013) was utilized to fit all the models.

\section{Results}

The distribution of daily singleton PTB, meteorological variables and air pollutants in Shenzhen were displayed in Table 1. The average number of daily singleton PTB in Shenzhen was 22.85 . The average daily PTB was different according to different delivery modes, infant's sex and maternal age. Among them, the age group of $20 \sim 34$ years reported the highest number of the PTB cases $(n=18.94)$, the next is female daily PTB, 13.06 , and then comes to vaginal delivery, 12.95 . The mean temperature was $23.14{ }^{\circ} \mathrm{C}$, and the temperature ranged from 5.40 to $32.70{ }^{\circ} \mathrm{C}$ during the study period. Shenzhen had an average relative humidity $70.89 \%$. Mean concentration of $\mathrm{NO}_{2}, \mathrm{PM}_{10}$ and $\mathrm{SO}_{2}$ were $46.37 \mathrm{~g} / \mathrm{m}^{3}, 61.11 \mathrm{~g} / \mathrm{m}^{3}$, and $18.01 \mathrm{~g} / \mathrm{m}^{3}$, respectively. And we also analyzed the lag effect of air pollutants on PTB (see Additional file 1: Table S1).

Table 2 presented the PTB rate in Shenzhen from 2005 to 2011 . There were a total of $58,411(5.61 \%$ of total eligible births) singleton PTB over the study period. The PTB rate of cesarean section was $1.24 \%$ higher than that of vaginal delivery. There was a higher percentage of PTB in boys compared with girls (5.90 \% vs. $5.27 \%)$, When stratified by maternal age, the maternal age 20 34 groups had the lowest PTB rate, which was $5.30 \%$.

In the sensitivity analyses, we adjusted the degrees of freedom (4, $6 \mathrm{df} /$ year) for temporal adjustment and the degrees of freedom (4-7 df) for meteorological variables, and the effects estimates for temperature on PTB remained similar. HRs for temperature and PTB of the best model which chosen a natural cubic spline for day of the year (DOY, with $\mathrm{df}$ of 5/year), and a natural cubic spline of meteorological with the degrees of freedom ( $5 \mathrm{df})$ were presented on $\mathrm{Ta}$ bles 3 and 4 . We added month as a covariate into the model, and the temperature effect estimates for PTB remained similar (see Additional file 1: Table S2 and S3).

The overall effect of temperature on PTB was illustrated in Fig. 2, showing a three-dimensional pattern of the RR along daily mean temperature and lag days (up to 30). The RR was calculated with the median of daily mean temperature $24.5{ }^{\circ} \mathrm{C}$ as the reference. The overall estimated association of temperature on PTB was

Table 1 Summary statistics of singleton PTBs, daily weather conditions and air pollutants in Shenzhen

\begin{tabular}{|c|c|c|c|c|c|c|}
\hline Variable & Mean(SD) & Min & P25 & P50 & P75 & Max \\
\hline Temperature $\left({ }^{\circ} \mathrm{C}\right)$ & $23.14(5.56)$ & 5.4 & 19.2 & 24.5 & 27.8 & 32.7 \\
\hline Humidity (\%) & $70.89(12.87)$ & 17 & 65 & 73 & 80 & 99 \\
\hline Atmospheric pressure (hpa) & 1006.07(6.61) & 985.7 & 1001.1 & 1005.90 & 1010.70 & 1029.10 \\
\hline $\mathrm{NO}_{2}\left(\mu \mathrm{g} / \mathrm{m}^{3}\right)$ & $46.37(20.40)$ & 10.67 & 31.77 & 41.75 & 56.38 & 166.13 \\
\hline $\mathrm{PM}_{10}\left(\mu \mathrm{g} / \mathrm{m}^{3}\right)$ & $61.11(32.19)$ & 12.38 & 35.75 & 53.88 & 80.17 & 411.50 \\
\hline $\mathrm{SO}_{2}\left(\mu \mathrm{g} / \mathrm{m}^{3}\right)$ & $18.01(11.63)$ & 2.88 & 9.50 & 15.06 & 22.96 & 105.67 \\
\hline All PTBs & $22.85(7.98)$ & 4 & 17 & 22 & 28 & 49 \\
\hline Maternal age $15 \sim 19$ group PTBs & $0.84(1.05)$ & 0 & 0 & 1 & 1 & 6 \\
\hline Maternal age $20 \sim 34$ group PTBs & 18.94(7.10) & 3 & 14 & 18 & 24 & 46 \\
\hline Maternal age $35 \sim 49$ group PTBs & $2.47(1.91)$ & 0 & 1 & 2 & 4 & 12 \\
\hline Male PTBs & $13.06(5.12)$ & 1 & 9 & 12 & 16 & 33 \\
\hline Female PTBs & $9.80(4.30)$ & 1 & 7 & 9 & 12 & 26 \\
\hline Vaginal delivery PTBs & $12.95(4.70)$ & 1 & 10 & 13 & 16 & 29 \\
\hline Cesarean section PTBs & $9.92(5.11)$ & 1 & 6 & 9 & 13 & 30 \\
\hline
\end{tabular}


Table 2 PTBs rate from 2005 to 2011 in Shenzhen

\begin{tabular}{|c|c|c|c|c|}
\hline Items & Births & Proportion (\%) & PTBS & Occurrence (\%) \\
\hline All & $1,040,638$ & 100 & 58,411 & 5.61 \\
\hline \multicolumn{5}{|l|}{ Year of births } \\
\hline 2005 & 94,335 & 9.07 & 5281 & 5.60 \\
\hline 2006 & 115,428 & 11.09 & 6379 & 5.53 \\
\hline 2007 & 146,934 & 14.12 & 7856 & 5.35 \\
\hline 2008 & 163,138 & 15.68 & 8995 & 5.51 \\
\hline 2009 & 158,953 & 15.27 & 8732 & 5.49 \\
\hline 2010 & 174,515 & 16.77 & 10,071 & 5.77 \\
\hline 2011 & 187,335 & 18.00 & 11,097 & 5.92 \\
\hline \multicolumn{5}{|l|}{ Maternal age } \\
\hline Maternal age $15 \sim 19$ group & 28,491 & 2.74 & 2135 & 7.49 \\
\hline Maternal age $20 \sim 34$ group & 913,845 & 87.82 & 48,409 & 5.30 \\
\hline Maternal age $35 \sim 49$ group & 80,976 & 7.78 & 6326 & 7.81 \\
\hline Other (including missing or implausible) & 17,326 & 1.66 & 1541 & 8.89 \\
\hline \multicolumn{5}{|l|}{ Sex of fetus } \\
\hline Male & 564,967 & 54.29 & 33,358 & 5.90 \\
\hline Female & 475,535 & 45.70 & 25,038 & 5.27 \\
\hline Uncertain & 136 & 0.01 & 15 & 11.03 \\
\hline \multicolumn{5}{|l|}{ Delivery mode } \\
\hline Vaginal delivery & 643,955 & 61.88 & 33,105 & 5.14 \\
\hline Cesarean section & 396,683 & 38.12 & 25,306 & 6.38 \\
\hline
\end{tabular}

non-linear. The figure represented different patterns of temperature effect on the risk of PTB depending on the modification indicator used. The RR estimates of the PTB for decreasing temperatures values followed a sharper pattern with several peaks of effect of variable magnitude according to temperature value and delay. When compared the result which added month as a covariate to further control of season (see Additional file 1: Figure S1) with Fig. 2, little difference was observed, and this result also indicated the validity of DLNM in controlling seasonal trend.

Table 3 described the relative risk of temperatures for preterm delivery at specific lag days $(0,5,10,15,20,25$, and 30 days), and the temperatures $(9.0,12.5,29.9$, and $30.7^{\circ} \mathrm{C}$ ), which corresponded to the 1st, 5th, 95th, and 99th percentiles of the temperature distribution. It was found that for all of the singleton PTB, $9.0^{\circ} \mathrm{C}$ and $12.5^{\circ} \mathrm{C}$ were associated with an increased occurrence of PTBs, with $9{ }^{\circ} \mathrm{C}$, $\mathrm{RR}=1.54$ (95\% CI: 1.36-1.75) exerted a stronger adverse effect than $12.5{ }^{\circ} \mathrm{C}, \mathrm{RR}=1.49$ (95\% CI: $1.35-1.63$ ) at lag 0 . A positive association was also found with lag of 5,25 to 30 days at $9^{\circ} \mathrm{C}$ while the lag of 5,15 to 25 days at $12.5^{\circ} \mathrm{C}$. The cumulative effect on PTB in $9{ }^{\circ} \mathrm{C}$ is lower than that in $12.5{ }^{\circ} \mathrm{C}$, with $\mathrm{RR}=1.72$ (95 \% CI: $1.28-2.33$ ) and $\mathrm{RR}=1.96$ (95 \%CI: 1.60-2.39), respectively. A negative association was found with lag of 10 to 30 days at 29.9 and $30.7{ }^{\circ} \mathrm{C}$. The cumulative effects of high temperature (95th and 99th percentiles) on PTB are RR $=0.69$ (95 \% CI: 0.60-0.80) and $\mathrm{RR}=0.62$ (95 \%CI: 0.52-0.74), respectively.

Table 3 also showed maternal age categories relative risk of the entire singleton preterm for temperatures (1st, 5 th, 95th, and 99th percentiles) with reference at $24.5^{\circ} \mathrm{C}$ at different days. The younger age (15 19 years) groups were only sensitive to low temperature (1st and 5 th percentiles). In contrast, high temperature was negatively correlated with PTBs in the age (20 to 34 years) and (35 49 years) groups. The effects of $12.5^{\circ} \mathrm{C}$ in the age groups of $15-19$, 20-34, 35-49 years were $\mathrm{RR}=1.62$ (95\% CI: 1.06-2.49), $\mathrm{RR}=1.54(95 \% \mathrm{CI}: 1.39-1.71)$ and $\mathrm{RR}=1.49$ (95\% CI: 1.16-1.91) on the current day, respectively. The cumulative effects (30 days) of $12.5{ }^{\circ} \mathrm{C}$ in the age groups of $15 \sim$ $19,20 \sim 34,35 \sim 49$ years were RR $=2.74$ (95 \% CI: $1.15-$ 6.52), $\mathrm{RR}=2.02$ (95\% CI: $1.63-2.51)$ and $\mathrm{RR}=2.27(95 \%$ CI: $1.36-3.79)$, respectively.

The protective effect of high temperature (95th and 99th percentiles) on the $(20 \sim 34$ years $)$ groups was more endurable compared with the $(35 \sim 49$ years $)$ groups. The cumulative effect at $30.7{ }^{\circ} \mathrm{C}$ was $\mathrm{RR}=0.64$ (95\% CI: $0.53-$ 0.78 ) and $\mathrm{RR}=0.57$ (95\% CI: 0.36-0.92), respectively.

Table 4 presented relative risk of the singleton PTB for temperatures (1st, 5th, 95th, and 99th percentiles) by sex-specific and delivery mode categories at different days with reference at $24.5{ }^{\circ} \mathrm{C}$. It showed that the 
Table 3 Maternal age categories relative risk (RR) and $95 \%$ confidence intervals (Cl) for total PTBs for temperature (1, 5, 95 and $99 \%$ percentiles) at Different lag days with reference at $24.5^{\circ} \mathrm{C}$

\begin{tabular}{|c|c|c|c|c|}
\hline & \multicolumn{4}{|l|}{$\mathrm{RR}(95 \% \mathrm{Cl})$} \\
\hline & $9^{\circ} \mathrm{C}$ & $12.5^{\circ} \mathrm{C}$ & $29.9^{\circ} \mathrm{C}$ & $30.7^{\circ} \mathrm{C}$ \\
\hline \multicolumn{5}{|l|}{ All PTBs } \\
\hline Lag0 & $1.54(1.36-1.75)^{*}$ & $1.49(1.35-1.63)^{*}$ & $0.95(0.87-1.02)$ & $0.96(0.88-1.05)$ \\
\hline $\operatorname{Lag} 5$ & $1.03(1.00-1.07)^{*}$ & $1.05(1.03-1.07)^{*}$ & $0.99(0.98-1.01)$ & $1.00(0.98-1.02)$ \\
\hline $\operatorname{Lag} 10$ & $1.00(0.97-1.02)$ & $1.01(0.99-1.02)$ & $0.99(0.97-1.00)^{*}$ & $0.98(0.97-1.00)^{*}$ \\
\hline $\operatorname{Lag} 15$ & $0.99(0.97-1.01)$ & $1.01(1.00-1.02)^{*}$ & $0.99(0.98-1.00)^{*}$ & $0.98(0.97-0.99)^{*}$ \\
\hline Lag20 & $1.00(0.98-1.01)$ & $1.01(1.00-1.02)^{*}$ & $0.99(0.98-1.00)^{*}$ & $0.98(0.97-0.99)^{*}$ \\
\hline $\operatorname{Lag} 25$ & $1.01(1.00-1.03)^{*}$ & $1.01(1.00-1.02)^{*}$ & $0.99(0.98-1.00)^{*}$ & $0.98(0.97-0.99)^{*}$ \\
\hline $\operatorname{Lag} 30$ & $1.04(1.00-1.07)^{*}$ & $1.01(0.99-1.03)$ & $0.99(0.97-1.00)^{*}$ & $0.98(0.96-1.00)^{*}$ \\
\hline Cumul & $1.72(1.28-2.33)^{*}$ & $1.96(1.60-2.39)^{*}$ & $0.69(0.60-0.80)^{*}$ & $0.62(0.52-0.74)^{*}$ \\
\hline \multicolumn{5}{|c|}{ Maternal age $15 \sim 19$ group PTBs } \\
\hline Lag0 & $1.50(0.85-2.67)$ & $1.62(1.06-2.49)^{*}$ & $1.03(0.74-1.42)$ & $0.96(0.66-1.40)$ \\
\hline $\operatorname{Lag} 5$ & $1.12(0.97-1.29)$ & $1.07(0.98-1.17)$ & $1.00(0.93-1.07)$ & $1.01(0.93-1.10)$ \\
\hline $\operatorname{Lag} 10$ & $1.00(0.90-1.12)$ & $1.01(0.95-1.07)$ & $0.97(0.93-1.02)$ & $0.98(0.92-1.04)$ \\
\hline Lag15 & $0.97(0.89-1.06)$ & $1.00(0.96-1.05)$ & $1.00(0.97-1.04)$ & $1.01(0.96-1.05)$ \\
\hline Lag20 & $0.98(0.90-1.07)$ & $1.00(0.96-1.05)$ & $1.02(0.98-1.05)$ & $1.01(0.97-1.06)$ \\
\hline $\operatorname{Lag} 25$ & $1.02(0.95-1.10)$ & $1.01(0.97-1.06)$ & $1.01(0.98-1.05)$ & $1.00(0.96-1.04)$ \\
\hline Lag30 & $1.07(0.92-1.25)$ & $1.02(0.93-1.12)$ & $1.01(0.94-1.08)$ & $0.98(0.90-1.07)$ \\
\hline Cumul & $3.72(0.95-14.60)$ & $2.74(1.15-6.52)^{*}$ & $1.04(0.56-1.94)$ & $0.93(0.43-2.00)$ \\
\hline \multicolumn{5}{|c|}{ Maternal age $20 \sim 34$ group PTBs } \\
\hline Lag0 & $1.61(1.40-1.85)^{*}$ & $1.54(1.39-1.71)^{*}$ & $0.95(0.87-1.03)$ & $0.98(0.89-1.08)$ \\
\hline $\operatorname{Lag} 5$ & $1.03(1.00-1.07)^{*}$ & $1.05(1.02-1.07)^{*}$ & $0.99(0.97-1.01)$ & $0.99(0.97-1.01)$ \\
\hline $\operatorname{Lag} 10$ & $1.00(0.98-1.03)$ & $1.01(1.00-1.03)^{*}$ & $0.98(0.97-1.00)^{*}$ & $0.98(0.97-1.00)^{*}$ \\
\hline Lag15 & $0.99(0.97-1.01)$ & $1.01(1.00-1.02)^{*}$ & $0.99(0.98-1.00)^{*}$ & $0.98(0.97-0.99)^{*}$ \\
\hline $\operatorname{Lag} 20$ & $0.99(0.97-1.01)$ & $1.01(1.00-1.02)^{*}$ & $0.99(0.98-1.00)^{*}$ & $0.98(0.97-0.99)^{*}$ \\
\hline $\operatorname{Lag} 25$ & $1.01(0.99-1.03)$ & $1.01(1.00-1.02)^{*}$ & $0.99(0.98-1.00)^{*}$ & $0.98(0.97-0.99)^{*}$ \\
\hline $\operatorname{Lag} 30$ & $1.03(1.00-1.07)^{*}$ & $1.01(0.98-1.03)$ & $0.98(0.97-1.00)^{*}$ & $0.98(0.96-1.00)^{*}$ \\
\hline Cumul & $1.74(1.25-2.42)^{*}$ & $2.02(1.63-2.51)^{*}$ & $0.70(0.60-0.82)^{*}$ & $0.64(0.53-0.78)^{*}$ \\
\hline \multicolumn{5}{|c|}{ Maternal age $35 \sim 49$ group PTBs } \\
\hline Lag0 & $1.53(1.10-2.13)^{*}$ & $1.49(1.16-1.91)^{*}$ & $0.92(0.75-1.13)$ & $0.94(0.75-1.20)$ \\
\hline Lag5 & $1.05(0.97-1.14)$ & $1.09(1.04-1.15)^{*}$ & $1.02(0.98-1.07)$ & $1.01(0.96-1.06)$ \\
\hline $\operatorname{Lag} 10$ & $0.94(0.88-1.00)^{*}$ & $1.00(0.96-1.03)$ & $1.00(0.96-1.03)$ & $0.99(0.95-1.03)$ \\
\hline Lag15 & $0.99(0.94-1.04)$ & $1.01(0.98-1.04)$ & $0.98(0.96-1.01)$ & $0.98(0.95-1.01)$ \\
\hline $\operatorname{Lag} 20$ & $1.02(0.97-1.07)$ & $1.02(0.99-1.05)$ & $0.98(0.96-1.00)^{*}$ & $0.98(0.95-1.01)$ \\
\hline $\operatorname{Lag} 25$ & 1.03(0.99-1.08) & $1.01(0.98-1.04)$ & $0.99(0.97-1.01)$ & $0.99(0.96-1.01)$ \\
\hline Lag30 & $1.04(0.95-1.14)$ & $1.00(0.95-1.05)$ & $1.00(0.95-1.04)$ & $1.00(0.95-1.05)$ \\
\hline Cumul & $1.86(0.86-4.04)$ & $2.27(1.36-3.79)^{*}$ & $0.66(0.45-0.98)^{*}$ & $0.57(0.36-0.92)^{*}$ \\
\hline
\end{tabular}

association of the 1 st percentile temperature $\left(9.0{ }^{\circ} \mathrm{C}\right)$ in males was similar to that in females, $\mathrm{RR}=1.58(95 \% \mathrm{CI}$ : 1.35-1.84), $\quad \mathrm{RR}=1.49$ (95 \% CI: $1.25-1.77)$ on the current day, respectively.

A positive association on lag 0 , lag 5, lag 25 and lag 30 at $9.0{ }^{\circ} \mathrm{C}$ was found in male preterm with the current day has the largest effect, $\mathrm{RR}=1.58$ (95\% CI: 1.35-1.84) while for female preterm, $9.0{ }^{\circ} \mathrm{C}$ was only correlated with PTBs increase on lag 0 , with $\mathrm{RR}=$ 1.49 (95 \% CI: 1.25-1.77). The positive association at 29.9 and $30.7{ }^{\circ} \mathrm{C}$ on female preterm was more endurable compared to the male preterm. For example, the 
Table 4 Sex-specific and Delivery models relative risk (RR) and $95 \%$ confidence intervals (CI) for total PTBs for temperature (1, 5, 95 and $99 \%$ percentiles) at different lag days with reference at $24.5^{\circ} \mathrm{C}$

\begin{tabular}{|c|c|c|c|c|}
\hline & \multicolumn{4}{|l|}{$\mathrm{RR}(95 \% \mathrm{Cl})$} \\
\hline & $9^{\circ} \mathrm{C}$ & $12.5^{\circ} \mathrm{C}$ & $29.9^{\circ} \mathrm{C}$ & $30.7^{\circ} \mathrm{C}$ \\
\hline \multicolumn{5}{|l|}{ Male PTBs } \\
\hline Lag0 & $1.58(1.35-1.84)^{*}$ & $1.49(1.33-1.67)^{*}$ & $0.96(0.88-1.06)$ & 0.98(0.88-1.09) \\
\hline Lag5 & $1.05(1.01-1.09)^{*}$ & $1.06(1.03-1.08)^{*}$ & $1.00(0.98-1.02)$ & $1.00(0.97-1.02)$ \\
\hline $\operatorname{Lag} 10$ & $0.99(0.97-1.02)$ & $1.01(0.99-1.02)$ & $0.99(0.97-1.00)^{*}$ & $0.98(0.96-1.00)^{*}$ \\
\hline Lag15 & $0.99(0.96-1.01)$ & $1.00(0.99-1.02)$ & $0.99(0.98-1.00)^{*}$ & $0.98(0.97-1.00)^{*}$ \\
\hline Lag20 & $1.00(0.98-1.02)$ & $1.00(0.99-1.02)$ & $0.99(0.98-1.00)^{*}$ & $0.98(0.97-1.00)^{*}$ \\
\hline $\operatorname{Lag} 25$ & $1.02(1.00-1.04)^{*}$ & $1.01(1.00-1.02)^{*}$ & $0.99(0.98-1.00)^{*}$ & $0.98(0.97-0.99)^{*}$ \\
\hline $\operatorname{Lag} 30$ & $1.06(1.01-1.10)^{*}$ & $1.02(0.99-1.04)$ & $0.99(0.97-1.02)$ & $0.98(0.96-1.01)$ \\
\hline Cumul & $1.97(1.37-2.83)^{*}$ & $1.96(1.54-2.49)^{*}$ & $0.74(0.62-0.88)^{*}$ & $0.64(0.52-0.80)^{*}$ \\
\hline \multicolumn{5}{|c|}{ Female PTBs } \\
\hline Lag0 & $1.49(1.25-1.77)^{*}$ & $1.48(1.30-1.68)^{*}$ & $0.93(0.84-1.03)$ & 0.95(0.84-1.08) \\
\hline $\operatorname{Lag} 5$ & $1.01(0.97-1.06)$ & $1.04(1.01-1.06)^{*}$ & $0.99(0.97-1.01)$ & 0.99(0.96-1.02) \\
\hline $\operatorname{Lag} 10$ & $1.00(0.97-1.04)$ & $1.01(0.99-1.03)$ & $0.98(0.97-1.00)^{*}$ & $0.98(0.96-1.00)^{*}$ \\
\hline Lag15 & $0.99(0.96-1.02)$ & $1.01(1.00-1.03)^{*}$ & $0.99(0.98-1.00)^{*}$ & $0.98(0.97-1.00)^{*}$ \\
\hline Lag20 & $0.99(0.96-1.02)$ & $1.01(1.00-1.03)^{*}$ & $0.99(0.97-1.00)^{*}$ & $0.98(0.97-1.00)^{*}$ \\
\hline $\operatorname{Lag} 25$ & $1.00(0.98-1.02)$ & $1.00(0.99-1.02)$ & $0.98(0.97-0.99)^{*}$ & $0.98(0.97-0.99)^{*}$ \\
\hline $\operatorname{Lag} 30$ & $1.01(0.97-1.06)$ & $0.99(0.96-1.02)$ & $0.97(0.95-1.00)^{*}$ & $0.97(0.95-1.00)^{*}$ \\
\hline Cumul & $1.40(0.92-2.12)$ & $1.94(1.48-2.55)^{*}$ & $0.64(0.52-0.78)^{*}$ & $0.60(0.47-0.76)^{*}$ \\
\hline \multicolumn{5}{|c|}{ Vaginal delivery PTBs } \\
\hline Lag0 & $1.36(1.18-1.57)^{*}$ & $1.29(1.16-1.44)^{*}$ & $0.93(0.85-1.01)$ & $0.92(0.84-1.02)$ \\
\hline Lag5 & $1.02(0.98-1.06)$ & $1.03(1.01-1.05)^{*}$ & $0.99(0.98-1.01)$ & $1.00(0.98-1.02)$ \\
\hline Lag10 & $1.01(0.98-1.04)$ & $1.02(1.00-1.03)^{*}$ & $0.98(0.97-1.00)^{*}$ & $0.98(0.96-0.99)^{*}$ \\
\hline Lag15 & $0.99(0.97-1.01)$ & $1.01(1.00-1.02)^{*}$ & $0.99(0.98-1.00)^{*}$ & $0.98(0.97-1.00)^{*}$ \\
\hline Lag20 & $0.99(0.97-1.01)$ & $1.00(0.99-1.02)$ & $0.99(0.98-1.00)^{*}$ & $0.98(0.97-0.99)^{*}$ \\
\hline $\operatorname{Lag} 25$ & $1.00(0.98-1.02)$ & $1.00(0.99-1.01)$ & $0.99(0.98-1.00)^{*}$ & $0.98(0.96-0.99)^{*}$ \\
\hline $\operatorname{Lag} 30$ & $1.02(0.98-1.06)$ & $0.99(0.97-1.02)$ & $0.98(0.96-1.00)^{*}$ & $0.97(0.94-0.99)^{*}$ \\
\hline Cumul & $1.58(1.12-2.22)^{*}$ & $1.67(1.33-2.10)^{*}$ & $0.69(0.58-0.81)^{*}$ & $0.58(0.48-0.71)^{*}$ \\
\hline \multicolumn{5}{|c|}{ Cesarean section PTBs } \\
\hline Lag0 & $1.78(1.46-2.17)^{*}$ & $1.76(1.52-2.04)^{*}$ & $0.97(0.86-1.09)$ & 1.02(0.89-1.18) \\
\hline Lag5 & $1.06(1.00-1.11)^{*}$ & $1.07(1.04-1.10)^{*}$ & $0.99(0.97-1.02)$ & $0.99(0.96-1.02)$ \\
\hline $\operatorname{Lag} 10$ & $0.98(0.95-1.02)$ & $1.00(0.98-1.02)$ & $0.99(0.97-1.01)$ & $0.99(0.97-1.01)$ \\
\hline Lag15 & $0.98(0.96-1.01)$ & $1.01(0.99-1.02)$ & $0.98(0.97-1.00)^{*}$ & $0.98(0.96-1.00)^{*}$ \\
\hline Lag20 & $1.00(0.97-1.03)$ & $1.01(1.00-1.03)^{*}$ & $0.98(0.97-1.00)^{*}$ & $0.98(0.96-1.00)^{*}$ \\
\hline $\operatorname{Lag} 25$ & $1.03(1.00-1.05)^{*}$ & $1.02(1.00-1.03)^{*}$ & $0.99(0.97-1.00)^{*}$ & $0.99(0.97-1.00)^{*}$ \\
\hline Lag30 & $1.06(1.00-1.12)^{*}$ & $1.02(0.99-1.05)$ & $0.99(0.97-1.02)$ & $1.00(0.96-1.03)$ \\
\hline Cumul & $1.93(1.21-3.08)^{*}$ & $2.33(1.71-3.16)^{*}$ & $0.70(0.56-0.88)^{*}$ & $0.68(0.51-0.90)^{*}$ \\
\hline
\end{tabular}

RR for $29.9{ }^{\circ} \mathrm{C}$ was 0.97 (95 \% CI: $0.95-1.00$ ) on lag 30 in female preterm. Differences were found when stratifying the analysis by delivery mode, positive association of 1st and 5th percentiles of temperature on PTBs of cesarean section groups were more obvious than that of vaginal delivery groups. The effect on lag
0 with the $\mathrm{RR}=1.78$ (95\% CI: $1.46-2.17$ ) in cesarean section preterm and $\mathrm{RR}=1.36$ (95\% CI: $1.18-1.57)$ in vaginal delivery preterm at $9.0{ }^{\circ} \mathrm{C}$. The cumulative effects (up to 30 days) of $9{ }^{\circ} \mathrm{C}$ in cesarean section and vaginal delivery PTBs are $\mathrm{RR}=1.93$ (95 \% CI: 1.21 308 ) and $\mathrm{RR}=1.58$ (95\% CI: 1.12-2.22), respectively 
a

All preterm births in Shenzhen

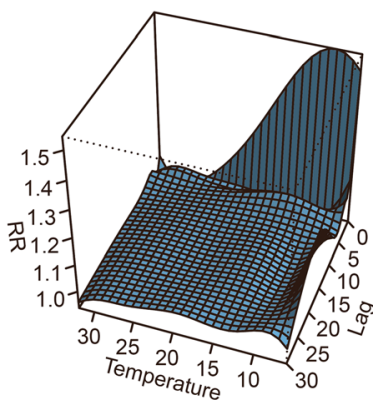

d

Maternal age 15-19 group preterm births in Shenzhen

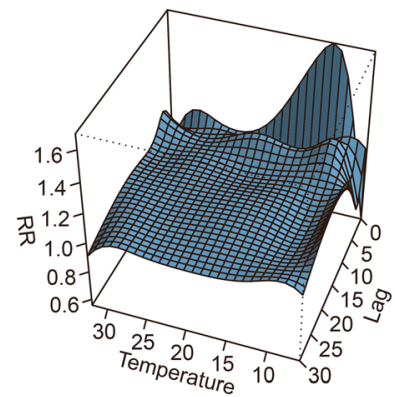

9

Vaginal delivery preterm births in Shenzhen

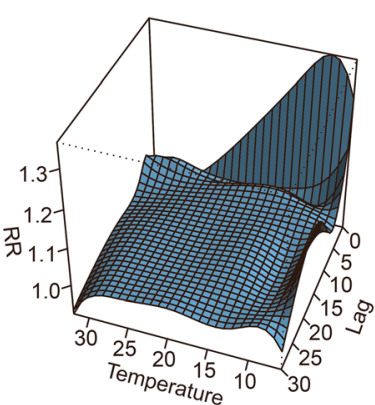

b

Male preterm births in Shenzhen

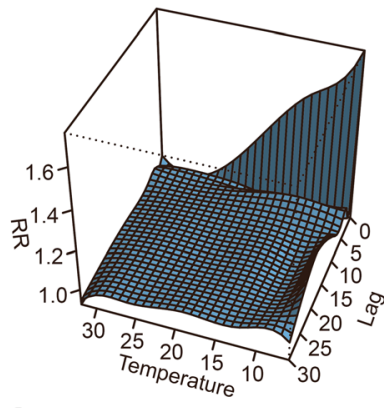

e

Maternal age 20-34 group preterm births in Shenzhen

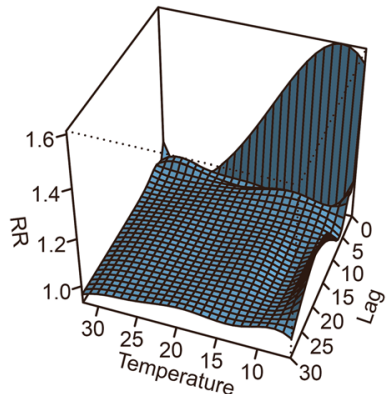

h

Cesarean section preterm births in Shenzhen

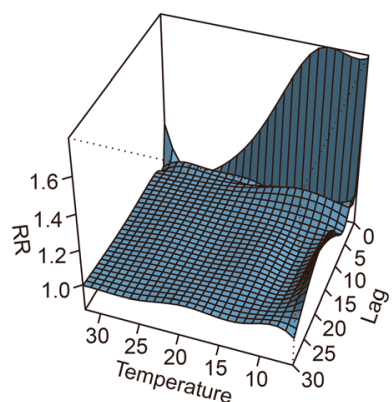

C

Female preterm births in Shenzhen

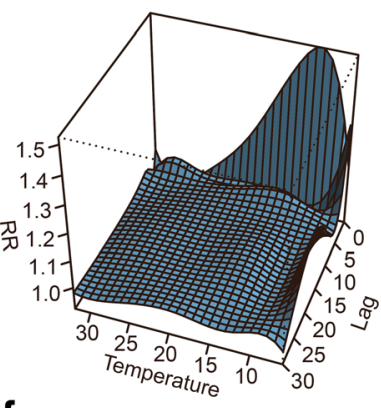

f

Maternal age 35-49 group preterm births in Shenzhen



Fig. 2 Three-D plot of RR along temperature and lags for PTB with reference at $24.5^{\circ} \mathrm{C}$ by DLNM method (Panel a is for all preterm births; $\mathbf{b}$ is for male preterm births; $\mathbf{c}$ is female preterm births; $\mathbf{d}$ is for preterm births with maternal age of 15-19 years; e is for preterm births with maternal age of 20-34 years; $\mathbf{f}$ is for preterm births with maternal age of 35-49 years; $\mathbf{g}$ is for vaginal delivered preterm births; and $\mathbf{h}$ is for cesarean section preterm births)

A positive association on lag 5,25 and lag 30 at $9.0^{\circ}$ $\mathrm{C}$ was also found in caesarian section preterm.

\section{Discussion}

Along with the increasing temperatures associated with climate change, interests have been increasing to examine the association between high temperature and human health, including preterm birth, such as researches reported by Liajinian [16], Porter [26], Yackerson [18], Basu [17], Dadvand [20], Strand [22], and Vicedo-Cabrera [21]. The previous studies [31] supported the association between the high temperature and the PTB. However, our study identified that in Shenzhen, high temperatures (95th and 99th percentiles) appears to be a protective factor on the PTB.

The protective effect of high temperature observed in this study was contrasting to a few previous studies. The potential biological mechanism remained largely unknown. Shenzhen is a subtropical and coastal city, even during the summer season, the high temperature is not as high as that in other cities. The average temperature was $23.14{ }^{\circ} \mathrm{C}$, and the 95th percentile of daily mean temperature was $29.9^{\circ} \mathrm{C}$ in Shenzhen during the study period. For example, in the studies in California, the average temperature was $31.5{ }^{\circ} \mathrm{C}$ 
and the 95th percentile temperature was $37.1{ }^{\circ} \mathrm{C}$ [17]. Dadvand's study in Spain had a temperature range of 27.9 $\sim 38.8{ }^{\circ} \mathrm{C}$, and the 95th percentile of temperature was $30.4{ }^{\circ} \mathrm{C}$ [20]. Shenzhen is a developed city with highest social-economic status, most people living in this city have access to air conditioner, so the exposure to higher temperature in summer was minimal, especially for the pregnant women.

A few studies have examined the association between the low temperatures and the PTB in developed countries. For example, studies in London and Rome did not find significant association between low temperatures and PTB $[24,27]$, while the Sweden study found that cold temperature was associated with an increased risk of PTB [25], which is consistent with our study. In our study, the low temperatures (1st and 5th percentiles) were significantly associated with increased risk of the PTB, and the strongest association was observed for lag 0 at $9{ }^{\circ} \mathrm{C}$ (5th percentile), which means much greater magnitude of cold temperature effect at lag 0, compared to cold temperature effects at greater lags. Shenzhen is located in low latitudes. According to prior studies, although the populations in low latitude have fewer opportunities to exposure to low temperatures, they have a low adaptation to low ambient temperature [41]. Compared with populations in high latitudes, they are more sensitive to the low temperatures $[42,43]$. The humid and cold weather in Shenzhen has more harmful effects on physiology compared with the dry and cold weather in other high latitude areas (London is in $51.5^{\circ}$ north latitude, and Rome is in $42^{\circ}$ north latitude). Shenzhen is in southeast of China, the residents do not routinely use heat radiators in winter, so they are exposed to a colder temperatures indoors in winter [44].

Only two previous studies $[17,22]$ considered whether the temperature was related to the sex of a preterm infant, and these studies did not report a significant association. Our findings are consistent with the two studies. Our study showed the association between the low temperature and the male PTB is similar to that of the female PTB while the protective effect of the high temperature in avoiding female PTB is more endurable.

We found a significant association of the low temperature with the risk of PTB in younger age (15 19 years) groups, indicating they were more susceptible to PTB. For the younger mothers, they may be in poor nutrition, poor physical status or have limited self-protection awareness and insufficient health service which may trigger PTB $[45,46]$. These early findings suggested that the health information about reducing exposure to cold temperatures should be emphasized in younger women. With this regard, more researches in other populations using different study design should be undertaken to determine the strength of the association and provide stronger evidence for this focused effort.
Recently, there was a report about the ambient temperature and the risk of preterm birth in Guangzhou, China. It showed that the cold temperature was associated with an increased risk of PTB [47]. Our finding was in accordance with this study. However, the high temperature might be a protective factor of the PTB in Shenzhen while it is a risk factor in Guangzhou. This result might be explained by the fact that the high temperature in Shenzhen is lower than that of Guangzhou, the 99th percentile is 30.7 and $31.9{ }^{\circ} \mathrm{C}$ respectively. And urban heat island effect in Guangzhou is more severe than that of Shenzhen [48]. Our study further classified singleton PTBs cohort according to different genders and maternal ages and analyzed the association of temperature on PTBs in those subgroups, which helps identify the susceptible groups and estimate the degree of influence in different subgroups. For the newborns in our study, the cesarean section presented $38.12 \%$, and cesarean section PTBs presented $43.32 \%$ of all the PTBs. Our study also divided PTBs into the vaginal delivery and cesarean section cohort, which can be more comprehensive to grasp the influence of the temperature for all the PTBs. However, there is a limitation that the data were not available on whether preterm labour was spontaneous or induced.

This is a large-scale and population-based epidemiologic study of the association between the temperature and the PTB in China. Much of the prior evidence for the PTB from the environment exposures were based on air pollution $[32,33,49,50]$, and studies reported statistically significant association between the seasonal patterns and preterm birth [38, 51-54]. In this study, the variables of the air pollution and the seasonality of birth were controlled and hopefully negated any potential confounding by them. On the other hand, a few limitations should be considered when interpreting findings from our study. First, in data collection, we used environmental monitoring data to represent the individual exposure level to weather conditions, which might not accurately reflect the real individual exposure. This exposure misclassification may be more important for the high temperatures than the low temperatures, due to the widespread use of air conditioners, but the limited use of heating devices may explain the significant associations between the high temperatures and the PTB identified by other studies. Second, we had to rely on the data provided on the birth certificates, and we did not have the information on several characteristics such as the socio-demographic and maternal health condition, thus we could not account for these variables in our analyses.

\section{Conclusions}

In Shenzhen, the low temperatures appeared to be the risk factor for the PTB, and the high temperatures might be a protective factor of the PTB. Differences in results 
of the delivery mode reflect differences in population susceptibility.

\section{Additional file}

Additional file 1: Table S1. Results of the lag effect of air pollutants $\left(\mathrm{NO}_{2}\right.$, $\mathrm{PM}_{10}$ and $\mathrm{SO}_{2}$ ) on preterm birth. Table $\mathbf{S 2}$. Maternal age categories relative risk (RR) and $95 \%$ confidence intervals (Cl) for total PTBs with month control for temperature (1, 5, 95 and $99 \%$ percentiles) at Different lag days with reference at $24.5^{\circ} \mathrm{C}$. Table S3. Sex-specific and Delivery models relative risk (RR) and $95 \%$ confidence intervals (Cl) for total PTBs with month control for temperature (1, 5, 95 and $99 \%$ percentiles) at different lag days with reference at $24.5^{\circ} \mathrm{C}$. Figure $\mathrm{S} 1$. Three-D plot of RR along temperature and lags for PTB with reference at $24.5^{\circ} \mathrm{C}$ by further control of month. (DOC $15271 \mathrm{~kb}$ )

\section{Abbreviations}

AIC, Akaike's information criterion; BP, barometric pressure; Cl, confidence interval; $\mathrm{df}$, the degrees of freedom; DLNM, distributed lag non-linear model; DOW, day of the week; DOY, day of the year; $\mathrm{PH}$, public holiday; $\mathrm{PM}_{10}$, particulate matter with aerodynamic diameter $\leq 10 \mu \mathrm{m}$; PTB, preterm birth; $\mathrm{RH}$, relative humidity; RR/RR(s), relative risk(s)

\section{Acknowledgement}

We want to thank Yan Lin, Lei Zhang, Xue Zhang, Li Li, Shaogiang Zhang, Yuli Cheng and Xiaomei Zhou for providing research data. The interpretations contained here do not represent the views of these agencies. And Shannon Rutherford, Luwen Zhang and Hualiang Lin help us improving the style of writing English.

\section{Funding}

Ministry of Environmental Protection Fund (21111011101EHH(2011)-208) (Pl: Qingguo Zhao) "The method of environmental and reproductive health survey" gave us basic support in the design of the study. Yan Lin, Lei Zhang, Xue Zhang, Li Li, Shaoqiang Zhang, Yuli Cheng and Xiaomei Zhou provided research data. Shannon Rutherford, Luwen Zhang and Hualiang Lin help us improving the style of writing English.

\section{Availability of data and supporting material}

Data were collected as mandatory work, and can be available throuth contact with the corresponding author.

\section{Authors' contributions}

QGZ and ZJL were involved in the development of the study's protocol design, data collection, data quality monitoring, data analysis and preparation of the manuscript. ZJL and YZM were involved in analysis and editing draft manuscripts. ZJL were involved mainly in data analysis and its data quality management. All authors contributed to the revision of the final manuscript. All authors read and approved the final manuscript.

\section{Authors' information}

Personal Statement of Qingguo Zhao: My research fields include: (1) Pioneered in air pollution and women's and children's health epidemiological studies in China, with a focus on the impact of air pollution and meteorological factors on reproductive health and pregnancy outcomes using birth certificates data. These efforts have resulted in a number of well-cited peer-reviewed articles, in both English and Chinese. (2) Extensive experience in leading large-scale multicenter data collection and epidemiological studies, for example the molecular epidemiological study of Thalassemia throughout the 21 metropolitan cities in Guangdong, and the study of reproductive health status and needs of unmarried floating population.(3) Led the construction of the Guangdong province women and children hospitals communication network system, which facilitate efficient sharing of information and data resources within system, and cost-effective quality control. (4) Extensive research participation in pregnant women and children' health.

\section{Competing interest}

The authors declare that they have no competing interests.

\section{Consent for publication}

No applicable

\section{Ethics approval and consent to participate}

This study was approved by the medical ethics committee of Guangdong Women and Children Hospital. Data used in this study were anonymous and no individual identifiable information was available for the analysis.

\section{Author details}

'Department of Public Health, Guangdong Women And Children Hospital, 521, 523 Xing Nan Street, Panyu District, 511442 Guangzhou, Guangdong, China. ${ }^{2}$ Department of Children Health Care, Shenzhen Women and Children Hospital, Shenzhen, Guangdong, China. ${ }^{3}$ Department of Information Network, Meteorological Bureau of Shenzhen Municipality, Shenzhen, Guangdong, China. ${ }^{4}$ Department of Public Health, Fu Tian Maternal and Children Health Hospital, Shenzhen, Guangdong, China. ${ }^{5}$ Department of Public Health, Luo Hu Maternal and Children Health Hospital, Shenzhen, Guangdong, China. 'Department of Public Health, Long Gang Maternal and Children Health Hospital, Shenzhen, Guangdong, China. ${ }^{7}$ Department of Public Health, Bao An Maternal and Children Health Hospital, Shenzhen, Guangdong, China. ${ }^{8}$ Fu Tian Hospital of TCM, Shenzhen, Guangdong, China. ${ }^{9}$ Guangdong Provincial Institute of Public Health, Guangdong Provincial Center for Disease Control and Prevention, Guangzhou, Guangdong, China.

Received: 12 January 2016 Accepted: 24 July 2016

Published online: 08 August 2016

\section{References}

1. World Health Organization. WHO: recommended definitions, terminology and format for statistical tables related to the perinatal period and use of a new certificate for cause of perinatal deaths. Modifications recommended by FIGO as amended October 14, 1976. Acta Obstet Gynecol Scand. 1977;56(3):247-53.

2. Blencowe H, Cousens S, Oestergaard MZ, Chou D, Moller AB, Narwal R, et al. National, regional, and worldwide estimates of preterm birth rates in the year 2010 with time trends since 1990 for selected countries: a systematic analysis and implications. Lancet. 2012;379(9832):2162-72. doi:10.1016/ S0140-6736(12)60820-4.

3. Liu L, Oza S, Hogan D, Perin J, Rudan I, Lawn JE, et al. Global, regional, and national causes of child mortality in 2000-13, with projections to inform post-2015 priorities: an updated systematic analysis. Lancet. 2014. doi:10. 1016/S0140-6736(14)61698-6.

4. Villar J, Papageorghiou AT, Knight HE, Gravett MG, lams J, Waller SA, et al. The preterm birth syndrome: a prototype phenotypic classification. Am J Obstet Gynecol. 2012;206(2):119-23. doi:10.1016/j.ajog.2011.10.866.

5. El-Sayed AM, Galea S. Explaining the low risk of preterm birth among arab americans in the United States: an analysis of 617451 births. Pediatrics. 2009; 123(3):e438-45. doi:10.1542/peds.2008-1634.

6. Ananth CV, Misra DP, Demissie K, Smulian JC. Rates of preterm delivery among Black women and White women in the United States over two decades: an age-period-cohort analysis. Am J Epidemiol. 2001;154(7):657-65.

7. Mattison DR, Wilson S, Coussens C, Gilbert D. The role of environmental hazards in premature birth: workshop summary: National Academies Press; 2003.

8. Rasmussen S, Irgens LM. The effects of smoking and hypertensive disorders on fetal growth. BMC Pregnancy Childbirth. 2006;6:16. doi:10.1186/1471-2393-6-16.

9. Andres RL, Day MC. Perinatal complications associated with maternal tobacco use. Semin Neonatol. 2000;5(3):231-41. doi:10.1053/siny.2000.0025.

10. Cleary-Goldman J, Malone FD, Vidaver J, Ball RH, Nyberg DA, Comstock CH, et al. Impact of maternal age on obstetric outcome. Obstet Gynecol. 2005; 105(5 Pt 1):983-90. doi:10.1097/01.AOG.0000158118.75532.51.

11. Conde-Agudelo A, Belizan JM, Lammers C. Maternal-perinatal morbidity and mortality associated with adolescent pregnancy in Latin America: cross-sectional study. Am J Obstet Gynecol. 2005;192(2):342-9. doi:10.1016/j.ajog.2004.10.593.

12. Lisonkova S, Janssen PA, Sheps SB, Lee SK, Dahlgren L. The effect of maternal age on adverse birth outcomes: does parity matter? J Obstet Gynaecol Can. 2010;32(6):541-8.

13. Machado CJ. Impact of maternal age on birth outcomes: a populationbased study of primiparous Brazilian women in the city of Sao Paulo. J Biosoc Sci. 2006;38(4):523-35. doi:10.1017/S0021932005026660.

14. Shah PS, Balkhair T. Air pollution and birth outcomes: a systematic review. Environ Int. 2011;37(2):498-516. doi:10.1016/j.envint.2010.10.009. 
15. Stieb DM, Chen L, Eshoul M, Judek S. Ambient air pollution, birth weight and preterm birth: a systematic review and meta-analysis. Environ Res. 2012; 117:100-11. doi:10.1016/j.envres.2012.05.007.

16. Lajinian S, Hudson S, Applewhite L, Feldman J, Minkoff HL. An association between the heat-humidity index and preterm labor and delivery: a preliminary analysis. Am J Public Health. 1997:87(7):1205-7.

17. Basu R, Malig B, Ostro B. High ambient temperature and the risk of preterm delivery. Am J Epidemiol. 2010;172(10):1108-17. doi:10.1093/aje/kwq170.

18. Yackerson N, Piura B, Sheiner E. The influence of meteorological factors on the emergence of preterm delivery and preterm premature rupture of membrane. J Perinatol. 2008;28(10):707-11. doi:10.1038/jp.2008.69.

19. Flouris AD, Spiropoulos Y, Sakellariou GJ, Koutedakis Y. Effect of seasonal programming on fetal development and longevity: links with environmental temperature. Am J Hum Biol. 2009;21(2):214-6. doi:10.1002/ajhb.20818.

20. Dadvand P, Basagana X, Sartini C, Figueras F, Vrijheid M, de Nazelle A, et al. Climate extremes and the length of gestation. Environ Health Perspect. 2011;119(10):1449-53. doi:10.1289/ehp.1003241.

21. Vicedo-Cabrera AM, Iniguez C, Barona C, Ballester F. Exposure to elevated temperatures and risk of preterm birth in Valencia, Spain. Environ Res. 2014; 134:210-7. doi:10.1016/j.envres.2014.07.021.

22. Strand LB, Barnett AG, Tong S. Maternal exposure to ambient temperature and the risks of preterm birth and stillbirth in Brisbane, Australia. Am J Epidemiol. 2012:175(2):99-107. doi:10.1093/aje/kwr404.

23. Wang J, Williams G, Guo Y, Pan X, Tong S. Maternal exposure to heatwave and preterm birth in Brisbane, Australia. BJOG. 2013;120(13):1631-41. doi:10. 1111/1471-0528.12397.

24. Schifano P, Lallo A, Asta F, De Sario M, Davoli M, Michelozzi P. Effect of ambient temperature and air pollutants on the risk of preterm birth, Rome 2001-2010. Environ Int. 2013;61:77-87. doi:10.1016/j.envint.2013.09.005.

25. Bruckner TA, Modin B, Vagero D. Cold ambient temperature in utero and birth outcomes in Uppsala, Sweden, 1915-1929. Ann Epidemiol. 2014;24(2): 116-21. doi:10.1016/j.annepidem.2013.11.005.

26. Porter KR, Thomas SD, Whitman S. The relation of gestation length to shortterm heat stress. Am J Public Health. 1999;89(7):1090-2.

27. Lee SJ, Hajat S, Steer PJ, Filippi V. A time-series analysis of any short-term effects of meteorological and air pollution factors on preterm births in London UK. Environ Res. 2008;106(2):185-94. doi:10.1016/j.envres.2007.10.003.

28. Wolf J, Armstrong B. The association of season and temperature with adverse pregnancy outcome in two German states, a time-series analysis. PLoS One. 2012:7(7):e40228. doi:10.1371/journal.pone.0040228.

29. Stan CM, Boulvain M, Pfister R, Hirsbrunner-Almagbaly P. Hydration for treatment of preterm labour. Cochrane Database Syst Rev. 2013;11: CD003096. doi:10.1002/14651858.CD003096.pub2.

30. Darrow LA, Klein M, Flanders WD, Waller LA, Correa A, Marcus M, et al. Ambient air pollution and preterm birth: a time-series analysis. Epidemiology. 2009;20(5):689-98. doi:10.1097/EDE.0b013e3181a7128f.

31. Carolan-Olah M, Frankowska D. High environmental temperature and preterm birth: a review of the evidence. Midwifery. 2014;30(1):50-9. doi:10.1016/j.midw. 2013.01.011.

32. Sagiv SK, Mendola P, Loomis D, Herring AH, Neas LM, Savitz DA, et al. A time-series analysis of air pollution and preterm birth in Pennsylvania, 19972001. Environ Health Perspect. 2005;113(5):602-6.

33. Zhao Q, Liang Z, Tao S, Zhu J, Du Y. Effects of air pollution on neonatal prematurity in Guangzhou of China: a time-series study. Environ Health. 2011:10:2. doi:10.1186/1476-069X-10-2.

34. Gasparrini A, Armstrong B. Time series analysis on the health effects of temperature: advancements and limitations. Environ Res. 2010;110(6):633-8. doi:10.1016/j.envres.2010.06.005.

35. Gasparrini A, Armstrong B, Kenward MG. Distributed lag non-linear models. Stat Med. 2010;29(21):2224-34. doi:10.1002/sim.3940.

36. Akaike H. Data analysis by statistical models. No To Hattatsu. 1992:24(2):127-33.

37. Darrow LA, Strickland MJ, Klein M, Waller LA, Flanders WD, Correa A, et al. Seasonality of birth and implications for temporal studies of preterm birth. Epidemiology. 2009;20(5):699-706. doi:10.1097/EDE.0b013e3181a66e96.

38. Strand LB, Barnett AG, Tong S. The influence of season and ambient temperature on birth outcomes: a review of the epidemiological literature. Environ Res. 2011;111(3):451-62. doi:10.1016/j.envres.2011.01.023.

39. Kinney PL, Schwartz J, Pascal M, Petkova E, Tertre AL, Medina S, et al. Winter season mortality: Will climate warming bring benefits? Environ Res Lett. 2015:10(6):064016. doi:10.1088/1748-9326/10/6/064016.
40. Guo Y, Barnett AG, Yu W, Pan X, Ye X, Huang C, et al. A large change in temperature between neighbouring days increases the risk of mortality. PLoS One. 2011;6(2):e16511. doi:10.1371/journal.pone.0016511.

41. Huang Z, Lin H, Liu Y, Zhou M, Liu T, Xiao J, et al. Individual-level and communitylevel effect modifiers of the temperature-mortality relationship in 66 Chinese communities. BMJ Open. 2015;5(9):e009172. doi:10.1136/bmjopen-2015-009172.

42. Wu W, Xiao Y, Li G, Zeng W, Lin H, Rutherford S, et al. Temperaturemortality relationship in four subtropical Chinese cities: a time-series study using a distributed lag non-linear model. Sci Total Environ. 2013; 449:355-62. doi:10.1016/j.scitotenv.2013.01.090

43. Curriero FC, Heiner KS, Samet JM, Zeger SL, Strug L, Patz JA. Temperature and mortality in 11 cities of the eastern United States. Am J Epidemiol. 2002;155(1):80-7.

44. Xie H, Yao Z, Zhang Y, Xu Y, Xu X, Liu T, et al. Short-term effects of the 2008 cold spell on mortality in three subtropical cities in Guangdong Province, China. Environ Health Perspect. 2013;121(2):210-6. doi:10.1289/ehp.1104541.

45. Khoury MJ, Stewart W, Weinstein A, Panny S, Lindsay P, Eisenberg M. Residential mobility during pregnancy: implications for environmental teratogenesis. J Clin Epidemiol. 1988;41(1):15-20.

46. Holditch-Davis D, Schwartz T, Black B, Scher M. Correlates of mother-premature infant interactions. Res Nurs Health. 2007:30(3):333-46. doi:10.1002/nur.20190.

47. He JR, Liu Y, Xia XY, Ma WJ, Lin HL, Kan HD, et al. Ambient temperature and the risk of preterm birth in Guangzhou, China (2001-2011). Environ Health Perspect. 2015. doi:10.1289/ehp.1509778.

48. Zhou D, Zhao S, Zhang L, Sun G, Liu Y. The footprint of urban heat island effect in China. Sci Rep. 2015:5:11160. doi:10.1038/srep11160.

49. Brauer M, Lencar C, Tamburic L, Koehoorn M, Demers P, Karr C. A cohort study of traffic-related air pollution impacts on birth outcomes. Environ Health Perspect. 2008;116(5):680-6. doi:10.1289/ehp.10952.

50. Ritz B, Wilhelm M, Hoggatt KJ, Ghosh JK. Ambient air pollution and preterm birth in the environment and pregnancy outcomes study at the University of California, Los Angeles. Am J Epidemiol. 2007;166(9): 1045-52. doi:10.1093/aje/kwm181.

51. Cooperstock M, Wolfe RA. Seasonality of preterm birth in the Collaborative Perinatal Project: demographic factors. Am J Epidemiol. 1986;124(2):234-41.

52. Keller CA, Nugent RP. Seasonal patterns in perinatal mortality and preterm delivery. Am J Epidemiol. 1983;118(5):689-98.

53. Rayco-Solon P, Fulford AJ, Prentice AM. Differential effects of seasonality on preterm birth and intrauterine growth restriction in rural Africans. Am J Clin Nutr. 2005;81(1):134-9.

54. Lee SJ, Steer PJ, Filippi V. Seasonal patterns and preterm birth: a systematic review of the literature and an analysis in a London-based cohort. BJOG. 2006;113(11):1280-8

\section{Submit your next manuscript to BioMed Central and we will help you at every step:}

- We accept pre-submission inquiries

- Our selector tool helps you to find the most relevant journal

- We provide round the clock customer support

- Convenient online submission

- Thorough peer review

- Inclusion in PubMed and all major indexing services

- Maximum visibility for your research

Submit your manuscript at www biomedcentral.com/submit
) Biomed Central 